\title{
AMIZADES: O DOCE SABOR DOS OUTROS NA DOCÊNCIA
}

\section{LUCIANA GRUPPELLI LOPONTE}

Professora adjunta do Departamento de Ensino e Currículo da Faculdade de Educação da Universidade Federal do Rio Grande do Sul Coordenadora do Grupo de Trabalho Educação e Arte, da Associação Nacional de Pós-Graduação em Educação lucianagl@terra.com.br

\section{RESUMO}

A amizade como um tema filosófico importante aparece de forma pontual nos últimos textos de Foucault, em especial no curso A hermenêutica do sujeito e em entrevistas. Pensar nos dias de hoje em conceitos como ascese ou amizade é um dos grandes desafios legados por Foucault. Para o filósofo, a amizade seria a reabilitação da estética da existência para o presente. Esse tema ainda é pouco explorado pelos estudos da obra foucaultiana, e menos ainda no campo da educação. Neste artigo, trago essas questões para o debate sobre formação docente, apresentando algumas das discussões desenvolvidas em pesquisa com um grupo de professoras de Arte na educação básica da região de Santa Cruz do Sul (RS). Problematizo a possibilidade de invenção-artista no processo de formação docente, vendo-a como uma ação necessariamente compartilhada, que ocorre na relação com os outros. Recupero para essa discussão a teorização de Michel Foucault sobre as práticas de si, que não se dissociam das relações intersubjetivas. Algumas perguntas, inspiradas pelas problematizações foucaultianas, são preocupações deste trabalho: 0 que podemos esperar da escola como locus de formação, ou da universidade como propulsora da formação docente? Que docência pode emergir de grupos de formação, de redes de amizade? FORMAÇÃO DE PROFESSORES - ARTE - MICHEL FOUCAULT - AMIZADE

\section{ABSTRACT}

FRIENDSHIP: THE SWEET FLAVOR OF OTHERS IN TEACHING. Friendship appears topically as an important philosophical subject in the last texts of Foucault, especially in The hermeneutics of the subject and in his interviews. To think of concepts such as ascesis or friendship today is one of the great challenges bequeathed by Foucault. For the philosopher, friendship would be the rehabilitation of the aesthetics of existence into the present. This theme has been little explored by studies of the Foucaultian work, and even less so in the field of education. In this article, these issues are brought to the debate regarding teacher education by presenting some of the discussions developed in the research carried out with a group of basic education Arts teachers in the region of Santa Cruz do Sul, at the state of Rio Grande do Sul. The text addresses the possibility of artistic invention in the process of teacher education as a problem and considers it as a necessarily shared action which occurs in the relation to others. In this discussion, I resort to 
Michel Foucault's theory of the practices of the self, which are not dissociated from intersubjective relations. Some questions inspired by the Foucaultian problematization are the object of concern in this text: What can be expected from schools as a locus of education or from universities as propellers of teacher education? What type of teaching can emerge from education groups and networks of friendship?

TEACHER EDUCATION - ART - MICHEL FOUCAULT - FRIENDSHIP

No filme $O$ gosto dos outros' acompanhamos a busca dos personagens de algum sentido para suas vidas: o gosto da vida, o sabor dos outros na própria existência, a superação das angústias pessoais no encontro com outros. Amor, amizade, relacionamentos, encontros, desencontros: o doce (e o amargo) sabor dos outros. Mas o que esses temas podem ter a ver com educação e, mais especificamente, com formação docente?

Francisco Ortega (2002, 2000, 1999) aprofunda o tema da amizade, recuperando essa discussão filosófica principalmente com base em Michel Foucault, mas também em Jaques Derrida, Hannah Arendt e outros. Embora, na maior parte do tempo, guardemos o assunto da amizade às nossas questões mais íntimas e privadas, este é um tema que acompanha a trajetória filosófica ocidental há séculos (Baldini, 2000)². Ortega propõe a discussão sobre a amizade de um ponto de vista político, ético e estético. A partir da amizade, pensar em uma ética da "boa distância", não em relações condescendentes, mas em relações instigantes e desafiantes que nos impulsionam ao inesperado, à invenção de si mesmo:

Vivemos em uma época de despolitização que exige uma reinvenção do político, entendido como o espaço do agir e da liberdade, da experimentação, do inesperado, do aberto, um espaço vazio, ainda a ser preenchido: a amizade

I. Le goût dês autres, 1999, França, Agnès Jaoui.

2. A amizade é um discurso filosófico aparece e desaparece ao longo do tempo. É interessante conferir o estudo de Vincent-Buffault acerca dos tratados e textos filosóficos sobre a amizade conforme sua evidência no mercado editorial do século XVIII e seu desaparecimento no século XIX, na França, principalmente: "A história se torna por vezes a da usura das palavras e dos discursos. Em vez de dissertar sobre a amizade, dialogamos a meia voz: falar já é quase uma confidência, um apelo. Fazer dela um tema geral beira a grandiloquência, a impudência do sentimentalismo, se não o peso de uma lição de moral" (1996, p.57). 
como exercício do político. A amizade constitui uma nova sensibilidade e uma forma de perceber diferente, baseada no cuidado e na encenação da "boa distância". Somos capazes de aceitar o desafio de pensar a amizade para além da amizade própria, de imaginar metáforas e imagens para nossas relações de amor e amizade, de usufruir o sabor doce dessa nova amizade? TALVEZ. (Ortega, 2000, p. I17)

○ "talvez" aqui é indício de experimentação, espaço aberto para invenção das relações consigo mesmo e com os outros. Trago essas questões para o debate sobre formação docente, apresentando algumas das discussões desenvolvidas em pesquisa com um grupo de professoras de Arte na educação básica na Universidade de Santa Cruz do Sul (Loponte, 2005). Neste trabalho, problematizei a possibilidade de invenção-artista no processo de formação docente em arte, vendo-a como uma ação necessariamente compartilhada, que se dá em relação com os outros. Recupero para a discussão a teorização de Michel Foucault sobre as práticas de si, que não se dissociam das relações intersubjetivas. As artes de si mesmo não são um exercício de solidão, embora isso possa transparecer aos mais desavisados e preocupados em encontrar nestas práticas sinais de uma suposta autoestilização foucaultiana. A invenção de si não é um ato puramente individual, narcísico: "O cuidado de si [...] está atravessado pela presença do Outro: o outro como diretor de existência, o outro como correspondente a quem escrevemos e diante de quem nos medimos, o outro como amigo que socorre, parente benfeitor" (Gros, 2004, p.507).

A amizade, tema que é apenas esboçado por Foucault em algumas entrevistas e no curso A hermenêutica do sujeito, seria a reabilitação da estética da existência para o presente. Essa é a principal tese de Francisco Ortega sobre o tema da amizade em uma trilogia (2002, 2000, 1999). A relação com os outros e o cuidado com os outros são fundamentais para a noção de cuidado de si na Antiguidade. $\bigcirc$ governo dos outros está estritamente relacionado com o aprendizado sobre o governo de si mesmo. E é nesse sentido que se inserem as práticas de si como a escrita e as relações de amizade. Essas práticas fazem parte das "invenções da humanidade" que podem ajudar a pensar o tempo presente e, mais especificamente, a pensar a formação docente (em arte ou não). 


\section{AMIZADE : SABER DE SI, SABOR DOS OUTROS}

Para Ortega (1999), pensar nos dias de hoje em conceitos como ascese ou amizade é um dos grandes desafios legados por Foucault. Este tema, no entanto, ainda é pouco explorado pelos estudos da obra foucaultiana, e menos ainda no campo da educação.

O tema da amizade, ou das redes de amizade, faz parte das análises de Foucault sobre as práticas de si antigas. Ao analisar a concepção epicúrea de amizade, por exemplo, ele afirma que a amizade é uma das formas que se dá ao cuidado de si: "Todo homem que tem realmente cuidado de si deve fazer amigos" (Foucault, 2004, p.240), porque é exatamente essa necessidade do cuidado de si a motivação para ter amigos.

Com Ortega e seu estudo sobre a amizade, com base em Foucault e outros autores, podemos redimensionar um tema que aparentemente pertence apenas a nossos assuntos mais privados e íntimos. E, mais do que isso, pensar a amizade como um espaço de sociabilidade que extrapola as relações familiares e de parentesco e que pode ser um espaço político interessante para se pensar a educação e, especificamente, grupos de formação docente. No imaginário sobre a amizade ainda, de certa forma, prevalecem as imagens de proximidade, de familiaridade, de fraternidade. Ortega (2000), apoiando-se em Arendt, Foucault e Derrida, afirma que essas metáforas familiares apenas ocultam o caráter político das relações de amizade. A proximidade em demasia oculta as diferenças, não possibilita a pluralidade nos relacionamentos.

Se não há um locus privilegiado para a política, como afirma Hanna Arendt ${ }^{3}$, a política pode irromper em qualquer lugar, como na arte, e nas próprias relações de amizade. Não precisamos pensar a política como algo exclusivo de partidos políticos ou daquelas pessoas denominadas "políticos", já sabemos disso. A amizade, esse doce sabor do outro, daquele que nos completa, ou que se diferencia de nós, nos faz mais vivos, mais parte desse mundo. Por que não reinventar a política mediante essas relações, que nos reinventam a cada dia? Aqui podemos novamente recuperar Hannah Arendt: "Enquanto a força é a qualidade natural de um indivíduo isolado, o

3. Sobre o pensamento de Hanna Arendt a respeito da política, escreve Ortega: "A política pode irromper em qualquer lugar, nas organizações de base, nos conselhos revolucionários, na mídia, na arte, ou na amizade como exercício do político, sempre que os indivíduos se inserem no mundo pela palavra e pelas ações e dão início a algo novo e inesperado" (2000, p.42). 
poder passa a existir entre os homens quando eles agem juntos, e desaparece no instante em que eles se dispersam" (200 I, p.2 I2).

Em um tempo de individualismo exacerbado, em que estamos imersos em uma cultura plenamente narcísica, qual é o espaço para a relação com o outro? Que outro faz parte da nossa vida? Que "outros" existem além das relações de parentesco, das relações familiares?

Muitas vezes amigos e amigas nos "salvam" com palavras e ações, e muitas vezes nos sentimos pessoas melhores pelas relações de amizade que construímos. Nossa subjetividade é também constituída nessas relações intersubjetivas, contraditórias, feitas de distância e proximidade. A amizade, como forma de subjetivação coletiva, não é, no entanto, o simples espaço de fusão com o outro ou de puro consenso, ou ainda uma relação compensatória de afeto. Mais do que isso, podemos pensar, a partir de Foucault, que há um potencial transgressor nas relações de amizade, como uma dobra, como resistência às relações de saber-poder. Como parte de toda a problematização sobre o cuidado de si, a amizade insere-se como um dos pontos de resistência possíveis contra o poder político, como uma das "novas formas de subjetividade" propostas por Foucault:

.... problema político, ético, social e filosófico de nossos dias não consiste em tentar liberar o indivíduo do Estado nem das instituições do Estado, porém nos liberarmos tanto do Estado quanto do tipo de individualização que a ele se liga. Temos que promover novas formas de subjetividade através da recusa deste tipo de individualidade que nos foi imposto há vários séculos. (1995, p.239)

Ortega ressalta o quanto a amizade como elemento transgressor interessa mais a Foucault do que sua suposta função compensatória. A amizade não é vista como uma forma de relação ou comunicação que ultrapasse as relações de poder, mas antes "representa um jogo agonístico e estratégico, que consiste em agir com a mínima quantidade de domínio. Falar de amizade é falar de multiplicidade, intensidade, experimentação, desterritorialização" (Ortega, 1999, p. I 57).

A interrogação ética e estética dos últimos trabalhos de Foucault tem um caráter marcadamente político e culmina, mesmo que de forma incipiente, nas discussões acerca de uma ética da amizade, a capacidade de formação estética das relações humanas, em "um tipo de relacionamento intenso e móvel, que 
não permita que as relações de poder se transformem em estados de dominação" (Ortega, 1999, p. 168).

Estamos ainda, com Foucault, pensando nestes espaços de resistência, nestes espaços para práticas de liberdade, espaços em que possamos exercer nossa subjetividade com a menor dominação possível. E então, pergunta Deleuze (1992, p. | 42), "qual é nossa ética, como produzimos uma existência artista, quais são nossos processos de subjetivação, irredutíveis a nossos códigos morais? Em que lugares e como se produzem novas subjetividades? Existe algo a esperar das comunidades atuais?".

Quais as comunidades atuais para se pensar a docência, ou mesmo para exercê-la, para construí-la? O que podemos esperar da escola como locus de formação, ou da universidade como propulsora da formação docente? Que docência pode emergir de grupos de formação, de redes de amizade? As perguntas, inspiradas pelas problematizações levantadas por Foucault, se atualizam nas preocupações deste artigo.

\section{Amizades, arte e docência}

Foucault pára. Os estudantes precipitam-se à sua mesa. Não para Ihe falar, mas para desligar os gravadores. Não há perguntas. Na confusão, Foucault está só. E Foucault comentará: "Seria preciso poder discutir o que propus. Por vezes, quando a aula não foi boa, bastaria pouca coisa, uma pergunta, para tudo reordenar. Mas esta pergunta nunca vem. $\mathrm{Na}$ França, o efeito do grupo torna impossível qualquer discussão real. E, como não há canal de retorno, o curso se teatraliza. Tenho com as pessoas presentes uma relação de ator ou acrobata. E, quando termino de falar, uma sensação de total solidão..." (Ewald, Fontana, 2004, p. 17)

Apenas a leitura dos cursos e livros e dos tantos ditos e escritos de Foucault não nos permitiriam imaginar esta cena descrita na apresentação do livro A hermenêutica do sujeito. A solidão de Foucault diante da audiência ávida do Collège de France, que ouve e grava atentamente cada palavra, cada comentário. Por que as perguntas não vêm? Respeito, veneração, idolatria perante a palavra de um grande filósofo? Não estávamos lá, nem compartilhamos daquela atmosfera privilegiada, mas continuamos a fazer perguntas, continuamos a pensar e estabelecer relações com aqueles ditos que felizmente chegaram até nós. 
A cena, a teatralização de um discurso sem um canal de retorno lembra uma sensação já conhecida por quem trabalha com formação docente. Vivi esta cena algumas vezes, que poderia ser descrita mais ou menos assim: Platéia cheia. Mais de 90 professores e professoras de várias áreas do ensino fundamental de um município pequeno do interior do Rio Grande do Sul. Assunto: ensino de Arte. Oito horas de imagens, palavras e discursos em defesa da arte como uma área de conhecimento tão importante quanto as outras, para uma maioria que pensa que arte se resume a 'trabalhinhos' nas datas comemorativas. Final do dia: cansaço, desgaste. Alguém levanta a mão: "Eu trouxe até tesourinha. Não íamos pintar, colar e recortar?". Como formadoras de professoras, precisamos ser um pouco atrizes, acrobatas, animadoras, chamar a atenção para palavras que soam distantes aos que nos ouvem, recheá-las de algum sentido. Há solidão, frustração (mesmo que também tenhamos satisfações).

$\bigcirc$ trabalho com um grupo docente traz assim uma outra cor para os processos de formação ${ }^{4}$. Menos acrobacia, mais aprofundamento das discussões. Menos solidão, mais vínculo entre participantes. Menos monólogo, mais polifonia de vozes. Menos cópia e reprodução, mais invenção e experimentação. Menos verticalidade das verdades, mais horizontalidade das relações e dos discursos verdadeiros em circulação.

$\mathrm{Na}$ análise das práticas de si antigas, mais especificamente da parrhesia (o falar verdadeiro), Foucault salienta a dupla organização - vertical e horizontal - em circulação nos grupos epicuristas: por um lado, um mestre, aquele que tem o direito a falar, e que tem autoridade sobre todos os alunos e por outro "uma série de relações horizontais, relações intensas, densas, fortes que são relações de amizade e que servirão à salvação recíproca" (Foucault, 2004, p.47I). A contradição é que, apesar de tematizar longamente sobre estas relações horizontais e redes de amizade que constituíam as técnicas de si, o próprio Foucault, na condição solitária de autoridade máxima do discurso nos seus cursos no Collège de France, não via a possibilidade de que ali se efetivasse um trabalho coletivo com suas próprias palavras.

4. O trabalho com grupos de formação docente tem sido destacado em algumas pesquisas como demonstra Damiani, Vellozo e Barros (2004), que apresentam uma revisão das investigações realizadas no Brasil e em outros países sobre grupos docentes e trabalhos colaborativos entre professores. Destaco também o trabalho realizado por Dickel et al. (2002), com grupos de professores de escolas públicas de Passo Fundo (RS). 
As aulas de Michel Foucault ocorriam às quartas-feiras, do início de janeiro ao fim de março. A assistência, muito numerosa, composta de estudantes, professores, pesquisadores, curiosos, muitos deles estrangeiros, mobilizava dois anfiteatros do Collége de France. Michel Foucault muitas vezes lamentou a distância que isto podia instalar entre ele e seu "público", e o pouco intercâmbio possibilitado pela forma do curso. Ele almejava um seminário que fosse lugar de um verdadeiro trabalho coletivo. Fez diferentes tentativas nesse sentido. Nos últimos anos, no final da aula, dedicava um longo tempo para responder às perguntas dos ouvintes. (Ewald, Fontana, 2004, p. 16)

trabalho de uma professora de arte na escola, seja qual for a sua formação, é geralmente um trabalho solitário. A disciplina de arte está um pouco deslocada em relação ao conjunto do currículo escolar, ou pelo seu caráter de algo especial para poucos eleitos, ou de algo sem muita relevância. No trabalho que tenho realizado com grupos de professoras, e sua escrita, surge um espaço para o encontro dessas solidões pedagógicas. Um espaço em que é entendido, ouvido, lido e escrito, onde se pode falar, contar as descobertas, as realizações, as conquistas deste lugar conflituoso e contraditório que é uma sala de aula 5 . E, além disso, um espaço em que se estabelecem vínculos, onde as relações de amizade se transformam em uma forma de resistência política, de reinventar o político, de reinventar-se. Se não podemos fugir das relações de poder, que pelo menos possamos jogar esse jogo com o mínimo possível de dominação - é disso que nos fala Foucault. As relações de amizade, que extrapolam as relações de parentesco, podem constituir este espaço de criação de novas formas de existência e de subjetivação, para nós mesmos.

E o que dizer das amizades entre mulheres? $\bigcirc$ tema das amizades femininas surge de forma sutil nos escritos de Foucault ${ }^{6}$ e é pouco tematizada

5. Um espaço talvez em que se possa viver a experiência, a possibilidade que algo nos aconteça e que requer um gesto de interrupção (Larrosa, 2002, p.24).

6. Na entrevista "Da amizade como modo de vida" ( 1981 ), Foucault comenta o livro Surpassing the love of men, de Lillian Faderman: "No prefácio, a autora diz que ela havia partido da ideia de detectar as relações homossexuais e se deu por conta de que essas relações não somente não estavam sempre presentes mas que não era interessante saber se se poderia chamar a isso de homossexualidade ou não. E que, deixando a relação desdobrar-se tal como ela aparece nas palavras e nos gestos, apareceriam outras coisas bastante essenciais: amores, afetos densos, 
por Ortega: "A suspeita em relação às amizades femininas coincide com o surgimento do feminismo. Sua patologização tem conduzido em nosso século à condenação de quaisquer sentimentos entre mulheres, que serão qualificados de lésbicos e doentios" (1999, p. 165). ${ }^{7}$ O que este tema suscita? Se prestarmos atenção no jogo discursivo apresentado pela mídia, o tema das amizades femininas aparece às vezes de forma bastante estereotipada, revelando um pensamento comum a respeito ${ }^{8}$.

A imagem pode nos ajudar a pensar um pouco mais sobre as amizades femininas. É uma escultura de Camille Claudel chamada As bisbilhoteiras, feita de mármore e bronze (ou em uma versão de ônix). São quatro mulheres. Estão em um canto, sentadas em dois bancos. O cenário é um vagão de trem, mas poderia ser uma sala, um quarto, até uma praça. As quatro mulheres estão nuas, dando um tom irreal à cena. Uma mulher fala, gesticula com as mãos. As outras curvam-se para ela, seus corpos todos estão à escuta. Do que ela fala? De que falam? Que segredo as une? Como se chamaria uma cena semelhante composta por homens? Certamente de forma diferente. A belíssima escultura de Claudel

maravilhosos, ensolarados ou mesmo, muito tristes, muito negros. Este livro mostra até que ponto o corpo da mulher desempenhou um grande papel e os contatos entre os corpos femininos: uma mulher penteia outra mulher, ela se deixa maquiar e se vestir. As mulheres teriam direito ao corpo de outras mulheres, segurar pela cintura, abraçar-se. $\bigcirc$ corpo do homem estava interditado ao homem de maneira muito mais drástica. Se é verdade que a vida entre mulheres era tolerada, é somente em certos períodos e depois do séc. XIX que a vida entre homens foi, não somente tolerada, mas rigorosamente obrigatória, simplesmente isso teve lugar durante as guerras".

7. Ver também o capítulo "Amizades femininas" (Ortega, 2002, p. I 5 I - I55) e Ortega (2000, p.59).

8. Ver, por exemplo, a campanha publicitária da cerveja Kaiser, veiculada no verão de 2003, em que um dos slogans era: "Só o que é bom merece uma Kaiser". Nas propagandas desta campanha mais divulgadas, dois belos atores globais enumeravam o que merecia ou não um copo da cerveja. Na lista do que "merece uma Kaiser", entre outras coisas, estava a praia cheia, o top less, a vizinha seminua na janela etc. Aparentando uma grande inovação, e talvez querendo dar uma resposta às críticas feministas de plantão, a Kaiser apresenta uma versão feminina da propaganda. Por alguns dias, ouvia-se o seguinte na TV, em tom de suspense: "Agora as mulheres também vão dizer o que merece ou não uma Kaiser". A referida propaganda, enfim, apresentada pela atriz Fernanda Torres, enumera a lista feminina do que "merece uma Kaiser": liquidação no shopping, o ator Marcos Palmeira e... amigas no banheiro. Sem entrar no mérito das demais escolhas, é interessante analisar como a amizade entre as mulheres surge aí. As amigas estão rindo, olhando-se no espelho, demonstrando uma cumplicidade e uma certa provocação à curiosidade masculina: o que as mulheres fazem juntas? $\bigcirc$ tom que prevalece é de futilidade, ambiente de fofocas, coisas sem importância. 
revela um pouco do cotidiano - tema um tanto inusitado para a França de 1894. Quatro mulheres, quatro vizinhas, quatro comadres, quatro amigas. De que falam as mulheres quando estão juntas? Pensaríamos, conforme o senso comum, que elas falam de amenidades, fofocas, ou de assuntos estritamente domésticos futilidades, nada importante... De que são feitas as amizades femininas?

\section{FIGURA I}

AS BISBILHOTEIRAS, CAMILLE CLAUDEL, I894/I905

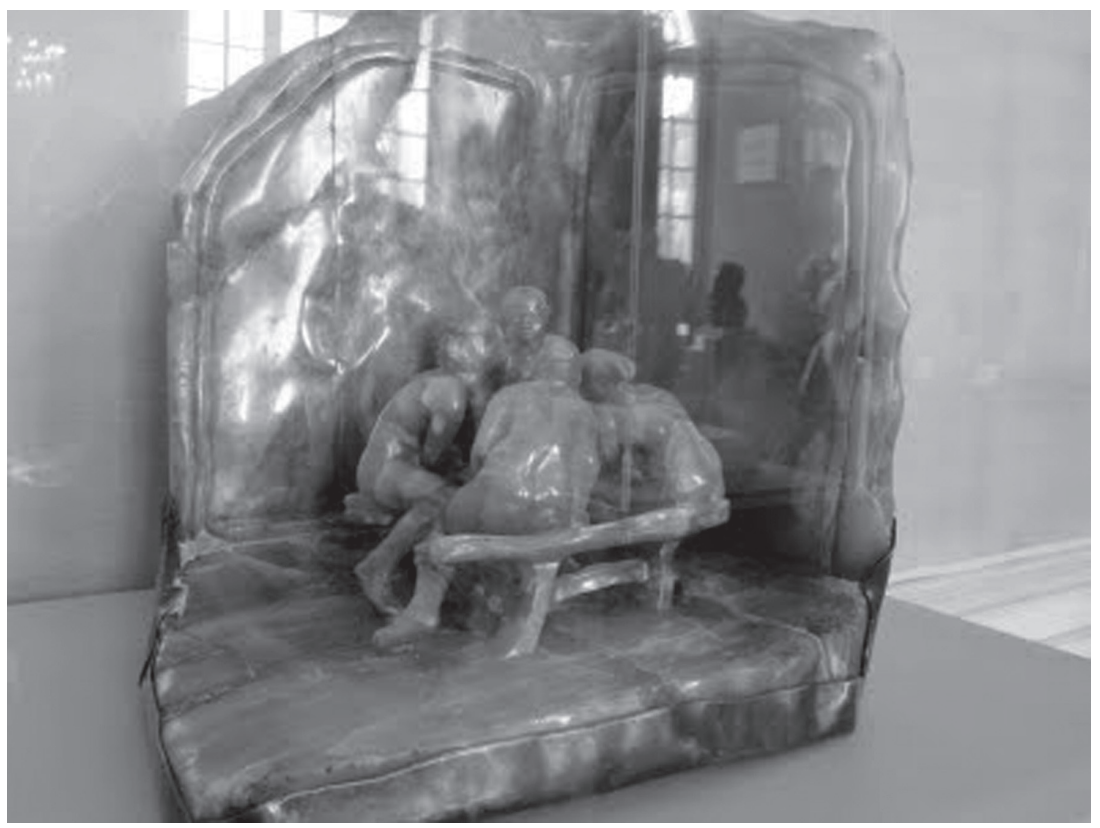

Que fazem afinal essas "bisbilhoteiras", essas mulheres, que vivem falando da vida alheia, ou ainda, as "amigas no banheiro", da propaganda de cerveja, em sua fútil aparência? Nossa imaginação pode transformar essas cenas no que quisermos. A questão que podemos pensar a partir daí é qual o papel do outro no nosso modo de pensar a política, ou na constituição da nossa própria subjetividade. Na conversa por nós apenas suspeitada entre as figuras de Camille Claudel, vê-se no entanto uma certa cumplicidade, manifestada no gesto de escuta, de atenção. Sempre houve desconfianças sobre as amizades femininas, 
tendo, desde a Antiguidade sido excluídas dos modelos canônicos e filosóficos de amizade. No entanto, hoje parece que há alguma condescendência para essas amizades que, na verdade, não são levadas muito a sério. Liberadas culturalmente para o afeto, o carinho, para a manifestação de sentimentos, as mulheres fortalecem suas amizades, apoiam-se mutuamente. Os homens ainda sofrem um olhar de condenação às manifestações de afeto com seus pares. Desde a descoberta e patologização da homossexualidade masculina, há uma restrição social às amizades entre os homens que não se contenham em formais apertos de mão e "tapinhas nas costas". A medicalização da homossexualidade colaborou, em certa medida, para a perda do caráter filosófico (e político) das relações de amizade. A amizade deixou de ser uma questão a ser pensada, para ser vivida apenas na intimidade.

Ortega procura reabilitar a questão na obra de Foucault, como uma possibilidade de experimentação de novas configurações das relações sociais, como possibilidade do inusitado, do novo, de reinvenção de nós mesmos.

Se olharmos bem para essas "mulheres bisbilhoteiras", desfazendonos de nossos estereótipos culturais, poderíamos perguntar: qual o potencial transgressivo das conversas entre mulheres 9 ? Qual o significado político de falar e ouvir ao outro? Que espaço ético-estético-político pode ser criado para as relações humanas e, mais especificamente, no âmbito da formação docente? O diálogo com a obra de Camille Claudel e também com as imagens estereotipadas da mídia pode-nos ajudar a pensar de outra forma, ou a estranhar esta relação saborosa que vivemos com o amigo, este "gosto do outro" que nos é tão próximo. Amigos, amigas, amizades femininas e masculinas ${ }^{10}-$ reinventar

9. Como exemplo, é importante lembrar a importância dos grupos de apoio para mulheres vítimas de violência, que se sentem mais fortalecidas diante dos seus agressores (trabalho realizado em centros de referência para as mulheres, casas de acolhida).

10. Sobre a diferença entre amizades femininas e masculinas, ver Vincent-Buffault ( 1996, p. I 80): "É provável que as amizades femininas e masculinas tenham evoluído de maneira diferente: no domínio das mulheres, dá-se lugar à sensualidade, ao contato, como à confidência, no prolongamento de uma relação de mãe para filha. A amizade viril definiu-se progressivamente em um ideal de ação e de convívio galhofeiro que desconfia da ternura e do excesso de intimidade, passada a idade da adolescência. [...] As imagens de virilidade, de autocontrole, afastam os homens da efusão, salvo ocasiões excepcionais, o que engendra momentos de relaxamento codificados na sociabilidade do beber ou na troca da fala libertina na ausência de mulheres. Essa fobia do contato se acompanha de uma idealização da virilidade". 
essas relações politicamente (e esteticamente) é, sem dúvida, reinventar o saber sobre nós mesmos.

\section{Alegria e prazer do encontro: estética das relações de amizade}

Desde o ano de 2000, um grupo de professoras de arte ou interessadas pelo tema reúne-se uma vez por mês para estudar, trocar experiências, aprender juntas. O cenário é a Universidade de Santa Cruz do Sul. Um grupo começou a se formar após alguns cursos de extensão oferecidos para a comunidade sobre arte e educação. Algumas professoras queriam mais do que simples receitas fáceis e "salvadoras" para suas aulas. Tem havido, durante esse tempo, descontinuidades, fracassos, dissidências, mudanças de rota e, claro, conquistas, pequenos sucessos. Uma pesquisa (Loponte, 2005) começou depois do início desse grupo e foi se envolvendo, tomando conta, mesclando-se. A pesquisa teve um fim, um ritual final, uma escrita que, ao menos no papel, precisou ser definitiva. $O$ grupo continua, anda com pernas próprias, não sabemos até quando". O efeito desse grupo de formação docente em Arte no trabalho de cada professora é visível. Há muitas escritas e registros dessas professoras em formas de pequenos textos, cartas, diários, portfólios - escritas de si que se completam com a leitura de outros. Algo que transcende as escritas são as relações fortes de amizade entre essas mulheres: "esse exercício da amizade forma e transforma: praticando-o, elaboram-se tanto o si mesmo quanto o entre-si. Indo ao encontro dos outros, é ao encontro de si mesma que a pessoa se lança" (Vincent-Buffault, 1996). Trago aqui algumas das análises sobre o efeito desta rede de amizades na constituição da docência.

Nas discussões do grupo, nos perguntávamos: o que fazemos juntas? $\bigcirc$ que faz, afinal, com que depois de cada encontro mensal queiramos voltar? Nas escritas que emergem no grupo, é possível perceber o prazer de estar juntas, a alegria de encontrar-se e partilhar descobertas, uma "festa de amigas". Longe do ranço de encontros "pedagógicos" e prescritivos, neste espaço de criação e invenção de relações consigo mesmo e relações com os outros, nos reinventamos como docentes.

I I. Uma outra pesquisa se iniciou em 2005, acompanhando os encontros do grupo e suas formas de registro, intitulada "Escritas de si (e para os outros) na docência em arte", com previsão de conclusão para julho de 2007. A respeito desta pesquisa ver Loponte (2006a). 
Que efeitos pode ter uma rede de amizades para a docência? Neste grupo, a arte é o tema comum, o elo de ligação, o aglutinador. Mas não só isso. Em torno da arte e seu ensino, encontram-se "as mesmas dúvidas, as mesmas angústias, as mesmas apreensões, os mesmos medos, os mesmos objetivos", é o que salta nas escritas. $\bigcirc$ "mesmo" quando compartilhado perde seu caráter de mesmice, de coisa sem importância; o "mesmo" adquire outros contornos, outra força. E o encontro dessas "solidões pedagógicas", características de muitas professoras de arte, modifica cada uma e a sua forma de atuar na docência, "não se é mais a mesma". Com a amizade,

...nunca mais a solidão será como antes. Em suas rajadas mais ardentes, mais destruidoras, a sensação de estar só desaparece em prol de uma amabilidade praticamente adquirida e de uma benevolência sempre disponível - o que não exclui nem a severidade, nem o rigor, pelo contrário. (Onfray, 1995, p. 174)

É preciso então pensar que em uma rede de amizades não se está imerso em um mar de condescendências e afabilidades incondicionais. Escuta-se, confessa-se, aceita-se, apazigua-se das inquietudes, mas também espera-se rigor, severidade, seriedade no discurso sobre o outro. E é justamente aí que se encerra o caráter político e transgressor das relações de amizade. Nietzsche prefere ter, no amigo, seu melhor inimigo: "Deves estar com o coração mais perto dele do que nunca, quando a ele te opões" (2003, p.83).

E é ele um dos primeiros filósofos a interromper a história da amizade como fusão, plena concordância e transparência, tal como o elogio à amizade celebrado em 1580, por Montaigne:

$\mathrm{Na}$ amizade a que me refiro, as almas entrosam-se e se confundem em uma única alma, tão unidas uma à outra que não se distinguem, não se thes percebendo sequer a linha de demarcação. Se insistirem para que eu diga por que o amava, sinto que não saberia expressar senão respondendo: porque era ele; porque era eu. (1996, p. 182)

Enquanto Montaigne fala das "amizades extraordinárias" como pura integração, Nietzsche aconselha o amor ao distante, não o "amor ao próximo" cristão: 
Não o próximo, eu vos ensino, mas o amigo. Que seja o amigo, para vós, a festa da terra e um presságio do super-homem. Eu vos ensino o amigo e seu transbordante coração. Mas é preciso que saiba ser uma esponja, quem quer ser amado por corações transbordantes. Eu vos ensino o amigo, que traz dentro de si o mundo pronto, um invólucro do bem - o amigo criador, que tem sempre um mundo pronto para dar de presente. (2003, p.88)

Esta nova noção rompe com o ideal clássico da amizade, pois, "no amigo, não devemos procurar uma adesão incondicional, mas uma incitação, um desafio para nos transformarmos. Tratar-se-ia de sermos capazes de viver uma amizade cheia de contradições e tensões, que permitisse um determinado agonismo e que não pretendesse anular as diferenças" (Ortega, 2000, p.80).

Mais do que uma simples "festa de amigas", um grupo de docentes com objetivos em comum é também a celebração da diferença, da distância, da alteridade. A amizade, neste sentido, não fortalece a identidade, o mesmo, mas se constitui como uma possibilidade de nos transformarmos, é "uma ascese, isto é, uma atividade de autotransformação e aperfeiçoamento" (Ortega, 2000, p.8I). E daí as relações de amizade não são apenas um espaço político, mas um espaço ético-estético, de invenção, criação, experimentação. A alegria e prazer desses encontros talvez se alojem justamente nessa poética das relações, nessa vontade artista de não ser mais a mesma, nessa vontade de extrapolar as relações burocráticas e sem vínculos a que muitas vezes se reduzem os espaços escolares, principalmente entre docentes. Talvez haja mesmo poucos espaços de criação para a docência na escola.

Uma questão recorrente no grupo é: estou no caminho certo? Buscase o "certo", a verdade da boa aula, da boa professora de arte. Algo como perguntar se é "certo" pintar um gato de azul ou imaginar outra cor para as árvores que não seja o óbvio verde. O sentido de pertencimento a um grupo, que dá suporte e acolhida às criações de cada uma, apazigua a intranquilidade da busca incessante pelo caminho mais lúcido e correto. Até porque, aprendemos juntas, o perseguido Santo Graal do caminho certo é pura ilusão. No grupo, nesta rede de amizades docentes, descobrimos que há caminhos verdadeiros, feitos dos caminhos e descaminhos trilhados individualmente e recriados quando compartilhados. Descobre-se então que se está "caminhando" bem quando ao reconhecer as mesmas angústias no 
outro, percebe-se a força do próprio trabalho. Identifico-me com o outro e me vejo diferente, "não sou mais a mesma", aos meus próprios olhos. A questão aí não é de identidade docente, mas sim de diferença. A partir do olhar do outro, de uma rede de amizades, produzo a diferença em mim mesma, me multiplico, me transformo.

Neste grupo docente, não há uma relação de sujeição ao outro, ou uma relação com o outro marcada pelo vínculo de obediência, como na tradição cristã. De algum modo, ainda somos herdeiros dessa forma de pensar a subjetividade, na qual a autoconstituição do sujeito acontece mediante o exame da consciência e da confissão, tendo como objetivo a renúncia de si e a autoanulação. Na constituição da docência, nos autoanulamos quando nos submetemos aos "manuais de autoajuda pedagógicos", com receitas práticas e rápidas de "como fazer" ou "como ser uma professora criativa (ou competente) em dez passos", renunciamos a nós mesmos diante de "palavras de salvação" de um discurso pedagógico, que promete a tomada de consciência crítica, plena e iluminada sobre os processos educativos.

Foucault traz para o debate ético atual os modos de subjetividade da tradição greco-romana, em que "o papel do outro é indispensável para a produção de um esboço de si compreensível. [...] para ele o outro está sempre presente na origem da constituição estética de si, na figura do mestre, guia, professor, diretor de consciência ou amigo"(Ortega, 1999, p. 132). A relação com o outro não se estabelece pela simples obediência, pela sujeição e submissão às verdades verticais, o que, por outro lado, não quer dizer também um falso democratismo dialógico. A relação com o outro está baseada na invenção, criação estética de si mesmo. Ao me olhar no outro, ao me reconhecer na diferença do outro, me transformo, me esculpo de modo distinto, e esse é um movimento constante que uma rede de amizades não cessa de efetuar. Por isso talvez essa vontade das professoras de sempre voltar ao grupo a cada encontro mensal, essa vontade de ser outra, de não ser a mesma outra vez.

grupo é um espaço permanente de exposições dos trabalhos realizados pelas professoras em sala de aula. A arte e a estética permeiam esse grupo de várias formas: a estética de si (pela escrita e pelas relações umas com as outras), as invenções artísticas delas (algumas das professoras são também artistas, pintam quadros, fazem trabalhos artesanais) e de seus alunos. Se nas 
escolas não há reconhecimento e valorização sobre o que fazem, naquele espaço coletivo a vibração com as conquistas de cada uma é constante. As imagens criadas pelos alunos e alunas da educação básica preenchem as pautas dos encontros, e em cada desenho, em cada novo trabalho apresentado, está a marca poética da professora, sob o olhar maravilhado, orgulhoso e cúmplice de todas. Do trabalho de uma professora se multiplicam outros, "idéias maraviIhosas" surgem a partir dos comentários coletivos. Projetos criados a partir da obra "O beijo", de Rodin, originando invenções tridimensionais com materiais diversos; criações a partir de desenhos de borboletas; objetos recriados a partir da leitura de artistas como Mondrian e Tarsila do Amaral; abstrações coloridas; bonecos articulados de papelão; pés e sapatos como "desculpa" para debater arte contemporânea com estudantes do ensino médio - são apenas alguns exemplos. Com o grupo aprendemos também a olhar juntas, a experienciar o sabor de imagens em exposições de arte como nas Bienais de Artes Visuais do Mercosul nos anos de 200 I e 2003. Para algumas delas, era um olhar estreante para exposições desse tipo, talvez mais saboroso porque compartilhado.

Nos últimos anos, nossos encontros mensais não estavam vinculados a nenhum curso de extensão, e constituímos um grupo de estudos, sem a necessidade de um certificado de conclusão. Para elas, é um "dia sagrado" preferível muitas vezes às reuniões da escola. E estar ali nem sempre é uma tarefa fácil, envolve deslocamento de municípios vizinhos a Santa Cruz do Sul (Venâncio Aires, Sinimbu, Sobradinho, por exemplo) e acertos com maridos e filhos. O grupo é o "nosso" grupo, espaço sagrado tecido por cada uma delas. $\mathrm{Na}$ apresentação para novas participantes, estampa-se no rosto o orgulho de pertencimento: "estou nesse grupo há dois anos", "estou aqui há três, quatro anos". O "aqui" é esse espaço subjetivo constituído e tramado por todas nós. Espaço de redes, rizomas, encontros dentro do encontro, uma obra de arte coletiva e intersubjetiva. Por meio da amizade:

...advém a singularidade de cada um, já que ela autoriza, na escultura de si, o recurso ao outro como a um espelho que se pode interrogar sem risco de obter um reflexo infiel. Ela reforça a intimidade contra as obrigações sociais e mundanas. Experimentando-a, pode-se medir o quanto nada resiste, diante dela, daquilo que faz habitualmente $o$ jogo social e a seriedade do mundo. A cumplicidade que ela gera é um desmultiplicador de força. Ela inscreve seu orgulho acima de 
todas as obrigações que não derivam de si. E como tal, é a virtude sublime por excelência. Porque não poderiam existir normas que a superem, ou leis que a contenham. (Onfray, 1995, p. 174)

As amizades não são obrigatórias, são escolhas, eleições éticas singulares. E é esse o caráter do grupo, longe das prescrições e obrigações burocráticas que muitas vezes caracterizam as reuniões escolares.

As escritas descrevem a força extraída da relação entre essas subjetividades docentes: "com o grupo nos fortalecemos", "o grupo me fez mais forte e me sinto mais capaz de ensinar arte". A cumplicidade desmultiplica forças, e o verbo próprio para engrenagens mecânicas indica uma redução de velocidade em favor de maior força. Porque talvez uma certa lentidão faça parte do processo, não é em um curso de pequena duração ou em uma palestra que se conquista a cumplicidade, que se trama uma rede sólida de confiança ou o sentido de criação coletiva.

Por que, no entanto, uma professora que trabalha com arte precisa de "força"? Para enfrentar a diretora que impõe o uso de desenhos mimeografados ("porque os pais pedem, porque os alunos gostam..."), para ir para o embate diante de colegas que não veem importância nenhuma em uma disciplina que não reprova e nem "cai" no vestibular, para conquistar uma sala adequada para arte, para conseguir o material mínimo para as aulas (folha, tinta, pincel, lápis de cor etc.), para apoderar-se de mais carga horária em meio a uma grade curricular que privilegia números e letras, para exigir professoras com formação específica em arte, e é claro que a lista não se encerra aí.

Nos bastidores do confronto quase sempre solitário na escola, há um grupo que pulsa, há todos aqueles discursos verdadeiros, compartilhados, debatidos, digeridos e transformados em verdades próprias. Incorporar, interiorizar, deixar-se subjetivar por esses discursos fortalece a docência em arte para que, nos jogos de poder (que aliam arte e feminino, por exemplo), se possa rolar os dados sem tanta dominação.

O espaço criado por essas relações de amizade docente não está imune às relações de poder, mas se configura como uma dobra, um modo de resistência em que se pode "brincar" de liberdade, ou dizendo de outra maneira, em que se experienciam práticas de liberdade, como parte de uma decisão ética singular e coletiva. Nos encontros não se buscam mais as receitas infalíveis que 
"salvarão" as aulas de cada uma e nem a palavra centralizadora e definitiva de um mestre que teria a chave para todas as respostas. Todas se comprometem de uma forma ou outra, todas se autorizam. E aí há os encontros dentro dos encontros, dobras entre as dobras, microrredes que se formam enquanto a cena principal das discussões acontece. Nessa relação entre ética, amizade e práticas de liberdade ninguém está repentinamente adquirindo poder, ou recuperando a "própria voz". As relações de poder estão em toda parte, a docência nunca é neutra e muda, mesmo que aparentemente se apresente desta forma.

Tal como a escrita, as relações de amizade que se estabelecem neste espaço coletivo são descontínuas, sujeitas a movimentos de maior agregação ou dispersão, maior ou menor velocidade, vácuos ou impasses, tal como a experiência própria dos artistas diante do impávido branco de telas e papéis: "que cor usar? Que misturas, que tonalidades? Qual é o melhor tema?" ou: "Será que elas vêm hoje? Que ritmo devem ter esses encontros? Mais prática, mais teoria?". Também fazem parte da criação a angústia, a ansiedade, a incerteza, esse "saber fazer fazendo", esse inventar-se sem regras pré-estabelecidas, o que não quer dizer o mesmo que falta de rigor ou o malfadado laissez-faire das práticas espontaneístas em ensino de arte.

Amizade entre mulheres, amizade transgressora entre professoras que têm aproximações distintas com a arte. Reinvenção de si mesmas e do espaço político e ético para a docência. Deixemos a imagem das "bisbilhoteiras", das "conversas de comadre", ou amizades condescendentes para trás. A formação docente pode se potencializar mediante os processos de subjetivação que envolvem as relações de amizade e escrita, não para descobrir ou desvelar afinal que professoras somos, mas para que outras invenções subjetivas vamos vestir, além das mesmidades escolares e pedagógicas. Há ainda muito a aprender com as amizades que desafiam, que instigam, que nos provocam (na distância e proximidade) a ser diferentes em uma sociedade que constantemente nos impõe modos de ser. $\bigcirc$ cultivo do "ethos da distância" é:

...em outras palavras, não utilizarmos o amigo para fortalecer nossa identidade, nossas crenças, isto é, 'o que somos', mas a possibilidade de concebermos a amizade como um processo, no qual os indivíduos implicados trabalham na sua transformação, invenção. Diante de uma sociedade que nos instiga a saber quem somos, a descobrir a verdade sobre nós mesmos, e que nos impõe uma determinada subjetividade, esse cultivo da distância na amizade levaria a subs- 
tituir a descoberta de si pela invenção de si, pela criação de infinitas formas de existência. (Ortega, 2000, p. I|4)

As discussões sobre a amizade realizadas por Foucault, centradas em algumas entrevistas nas relações homossexuais, apontam para "a capacidade da formação estética das relações humanas" (Ortega, 1999, p. 167). A noção de "programa vazio" (Foucault, 2005), no âmbito da atualização de uma estética da existência, é central na teorização foucaultiana e útil na pretensão de trazer essa discussão sobre amizade para outras esferas, como a formação docente. Esta noção de "programa vazio", conserva a forma, a ideia, mas abre a possibilidade de criação de uma "cavidade" que pode ser preenchida de forma diferente pelo indivíduo ou grupos de indivíduos (Ortega, 1999, p. 167, nota 48).

$\mathrm{Na}$ cavidade de um programa ético e estético, em um entre-espaço da escrita de si e as relações de amizade, podemos fazer habitar uma docência artista. Uma docência que se faz artista, que aprende com os artistas "a arte de se "pôr em cena' para si mesmo" ou a ousadia de sermos "poetas-autores de nossas vidas" (Nietzsche, 200।, § 78 e 299). Mais amizade e arte para a docência: por que não?

\section{REFERÊNCIAS BIBLIOGRÁFICAS}

ARENDT, H. A Condição humana. 10.ed. Rio de Janeiro: Forense Universitária, 200 I.

BALDINI, M. (org.) Amizade \& filósofos. Bauru: Edusc, 2000.

DELEUZE, G. Conversações (1972-1990). Rio de Janeiro: Editora 34, 1992.

DAMIANI, M. F.; VELLOZO, K. B.; BARROS, R. R. Por que o trabalho colaborativo entre professores é importante? Que evidências há sobre isso? In: ANPED SUL: SEMINÁRIO DE PESQUISA EM EDUCAÇÃO DA REGIÃO SUL, 5, 2004, Anais... Curitiba: Pontifícia Universidade Católica do Paraná, 2004. p.323.

DICKEL, A. et al. Em um processo de formação continuada, a possibilidade de articulação entre teoria e prática: reflexões sobre uma experiência compartilhada. In: ANPED SUL: SEMINÁRIO DE PESQUISA EM EDUCAÇÃO DA REGIÃO SUL, 4, Anais... Florianópolis: UFSC, NUP, CED, 2002. p.64.

EWALD, F;; FONTANA, A. Apresentação. In: FOUCAULT, M. A Hermenêutica do sujeito. São Paulo: Martins Fontes, 2004. p. I5-20. 
FOUCAULT, M. Da amizade como modo de vida. [Entrevista a R. Ceccaty, J. Danet e J. le Bitoux). Gai Pied, n.25, p.38-39, abr. 198I. (Trad.: Wanderson Flor do Nascimento). Disponível em: http://www.unb.br/fe/tefffiloesco/foucault/. Acesso em: 12 mar. 2005.

A Hermenêutica do sujeito. São Paulo: Martins Fontes, 2004.

O Sujeito e o poder. In: DREYFUS, H.; RABINOW, P. Michel Foucault, uma trajetória filosófica: para além do estruturalismo e da hermenêutica. Rio de Janeiro: Forense Universitária, 1995. p.231-249.

GROS, F. Situação do curso. In: FOUCAULT, M. A Hermenêutica do sujeito. São Paulo: Martins Fontes, 2004. p.613-661.

LARROSA, J. Notas sobre a experiência e o saber da experiência. Revista Brasileira de Educação, Rio de Janeiro, n. 19, p.20-28, jan./abr. 2002.

LOPONTE, L. G. Docência artista: arte, estética de si e subjetividades femininas. Porto Alegre, 2005. Tese (dout.) Programa de Pós-Graduação em Educação, Faculdade de Educação, Universidade Federal do Rio Grande do Sul.

Docência artista: arte, gênero e ético-estética docente. Educação em Revista, Belo Horizonte, n.43, p.35-55, 2006.

Escritas de si (e para os outros) na docência em arte. Educação, Santa Maria, v.31, p.295-304, 2006a.

MONTAIGNE, M. de. Ensaios, I: Da amizade. São Paulo: Nova Cultural, 1996.

NIETZSCHE, F. Assim falou Zaratustra: um livro para todos e para ninguém. 12.ed. Rio de Janeiro: Civilização Brasileira, 2003.

A Gaia ciência. São Paulo: Companhia das Letras, 200I .

ONFRAY, M. A Escultura de si: a moral estética. Rio de Janeiro: Rocco, 1995.

ORTEGA, F. Amizade e estética da existência em Foucault. Rio de Janeiro: Graal, 1999. . Genealogias da amizade. São Paulo: lluminuras, 2002.

Para uma política da amizade: Arendt, Derrida, Foucault. Rio de Janeiro:

Relume-Dumará, 2000.

VINCENT-BUFFAULT, A. Da amizade: uma história do exercício da amizade nos séculos XVIII e XIX. Rio de Janeiro: Jorge Zahar, 1996.

Recebido em: julho 2007

Aprovado para publicação em: abril 2008 